\title{
Needs Assessment: Knowledge on Parenting and Improving the Learning Space through Technological Advances in Afghanistan
}

\author{
Shahnaz Qayumi ${ }^{1}$, George Pachev ${ }^{2}$, Shabnam Hazrati³, Habib Sahar ${ }^{3}$, \\ Son Vuong', Karim Qayumi ${ }^{5}$ \\ ${ }^{1}$ Center of Excellence for Simulation Education and Innovation, Vancouver, Canada \\ ${ }^{2}$ University of British Columbia, Vancouver, Canada \\ ${ }^{3}$ Education \& Psychology Faculty of Kabul University, Center of Excellence for Innovation and Research, Kabul, \\ Afghanistan \\ ${ }^{4}$ Computer Sciences \& Technology Faculty, University of British Columbia, Vancouver, Canada \\ ${ }^{5}$ Center of Excellence for Simulation Education and Innovation, University of British Columbia, Vancouver, \\ Canada \\ Email: sarah@can-health.org
}

Received 22 April 2014; revised 18 May 2014; accepted 25 May 2014

Copyright (C) 2014 by authors and Scientific Research Publishing Inc.

This work is licensed under the Creative Commons Attribution International License (CC BY).

http://creativecommons.org/licenses/by/4.0/

(c) (i) Open Access

\begin{abstract}
There is a perception that war and illiteracy have created a gap in knowledge on parenting amongst parents in developing countries in general, but especially in post conflict countries such as Afghanistan. This knowledge gap may have subsequent negative effect on the future generations. There is also concern that parents in developing countries may not be open to receiving modern theories of childrearing. Therefore, the objective of this study was to conduct a needs assessment survey of Afghan parents with two specific aims: to estimate the need for knowledge on modern theories of early childhood development, and to determine if Afghans are open to receiving modern theories of early childhood development using technological advances such as learning through mobile phones. A survey questionnaire was designed and distributed amongst 240 families in Afghanistan. Results of the survey demonstrated a clear need for education of parents in Afghanistan, and proved that women and illiterate populations are at a disadvantage to receive this type of information. Moreover, the study demonstrated that Afghan families are open to receiving information on childrearing and that knowledge dissemination through technological advances will be acceptable.
\end{abstract}

\section{Keywords}

Health Education, Needs Assessment, Technology-Empowered Learning 


\section{Introduction}

According to studies by the World Literacy Foundation, "Illiterate parents tend to have lower expectations and aspirations regarding education for themselves and their children. Poor families often place work before education and the children of parents who have failed to complete primary education tend to do the same.” The cost of illiteracy to the global economy is estimated at USD \$ 1.19 trillion (Cree et al., 2012).

Young parents in Afghanistan have lived their whole lives in an environment of war, where school doors were often closed to them. During this period, millions of Afghans lived as refugees in Iran, Tajikistan, Pakistan, or India, returning after the fall of the Taliban to their ravaged nation, now with young children to raise (Palau, 2013). Thus, three decades of war in Afghanistan have created generations of illiterate parents, which has a subsequently detrimental effect on future generations.

After the fall of the Taliban, international communities accomplished a great deal of success in the reconstruction of the education system in Afghanistan (Jacobson, 2011). As a result, 9.5 million children (boys and girls) attended school (UNICEF, 2007). Nevertheless, the education system in Afghanistan is far from perfect and requires consistent efforts for its further improvement (Smith \& Todaro, 2009). It is undeniable that parents in Afghanistan send their children to work while they are studying (Smith \& Todaro, 2009), creating additional illiterate generations that subsequently push the society into a negative spin. Therefore, it is of the utmost importance that this cycle be broken by educating parents.

There is an assumption that the reality of placing work over education is driven by poverty (Ki-Moon, 2007). We believe that in addition to poverty, the knowledge gap and lack of awareness are also the factors in the behaviour of the parents. The lack of knowledge and understanding of modern theories of early childhood education may affect children not only in their cognitive development, but also in other aspects of development such as physical, social, emotional, and language development. In addition it is extremely difficult to deliver knowledge to those in need, due to the absence of roads, modes of transportation, costs associated with publication, delivery and illiteracy. In analyzing scientific literature we were not able to find relevant information with regards to understanding modern scientific theories of early childhood education amongst Afghan populations, nor on the willingness of Afghans to study, accept and implement modern scientific theories of early childhood development in their families. Finally we were not able to find a study that indicates the use of state-of-the-art technology for the enhancement of a learning space in this area (early childhood education).

We hypothesize that 35 years of war and illiteracy have created a knowledge gap in parenting education in Afghanistan; Afghan parents are open to receiving contemporary education in childrearing through technologically enhanced delivery.

Therefore, the objective of this study is to explore this knowledge gap and the acceptability of technologically enhanced educational delivery. The following research questions guided our inquiry:

- Is there a need to educate parents in the upbringing of their children?

- What aspects of parenting would be the best targets for educational intervention?

- Would those who agree that there is a need for such a program also be equipped for, and open to, an educational program delivered by technology such as M-Learning?

\section{Method}

\subsection{Participants}

Participants were representatives from 224 households living in the less-affluent neighborhoods of Kabul and its surrounding villages. Participants were recruited by members of the M-learning team, who knocked on every third door on the streets assigned to them. Those who expressed interest in participating in the project were enrolled in the study.

\subsection{Instruments}

For the purposes of the study, a questionnaire was developed with three sections. The demographic section included the gender of respondent, the main language in the household, marital status, level of education, and the number of children in the household. We further inquired whether the participant 1) considered understanding their children important; 2) whether they felt they needed more knowledge on parenting, and 3) whether they would be interested in participating in the M-learning project (“...take some lessons by phone...”). All three questions in this section required Yes/No responses. A set of 15 items described parenting behaviors and re- 
quired the respondent to identify how often they would enact this behavior: never, when I can, sometimes, most of the time, or always. The behaviors were from two types: 1) expressing affection, care, and support ("nurture"), for example, "I tune into my child’s emotional needs"; and 2) related to discipline and providing "structure", for example, "I am consistent in limit-setting and discipline". The purpose of including this section in the questionnaire was to obtain more detailed information on the parenting practices and respectively, the needs for parenting information. We also aimed to explore eventual differences in the responses of different ages, genders and education levels.

The second methodological approach in this study included interviews with parents to ensure they were confident in the answers provided for the survey questions, and that there was no misunderstanding or misperception. Additional interview questions were mainly on the feelings of the participants about the project as a whole, the process, attitudes of the field reviewers, family dynamics with respect to the upbringing of their children and others. We trained all assistants to conduct the interviews without bias or interference with the parents' thoughts.

\subsection{Procedure}

Twelve students from the Department of Education and Psychology at Kabul University were recruited as research assistants. These research assistants were trained to explain the objectives and procedures of the study, to elicit agreement/or disagreement to participate, and how to assist the completion of the questionnaire and answer common questions by respondents.

Conditional on expressed agreement to participate, the questionnaire was administered by the interviewer, usually immediately after obtaining consent. The questions were read and the answers recorded by the interviewer, who also provided explanations (but not suggestions) if the questions were not clear.

\subsection{Analyses}

The demographic information is summarized by descriptive statistics. We tried to evaluate the representativeness of the sample on a number of characteristics by comparing our obtained statistics to statistics from national and international survey documents.

The three questions about the value and interest of participating in the M-Learning project were used to form the pool of participants in the M-Learning implementation.

Descriptive statistics were used to build profiles of parenting behaviors for the group, as a whole and for gender, age and education groups. Correlational analyses were used to evaluate the association of gender, age and education groups with specific "structure" and "nurture" profiles.

\section{Results}

The respondents to the survey, representing 224 households, had a mean age of 35 years (SD = 9, range: 19 - 65). These numbers are in accordance with other sources (Millennium Development Goals, 2012), noting the significant "youth bulge" in Afghanistan's population, where $42 \%$ of the population are under the age of 15 , and $68 \%$ are under the age of 25.

Twelve percent of respondents reported no children in care in the household. The majority of households had from 1 to 5 children in care, with a mode (21\%) of 2 children. The remaining $11 \%$ of respondents reported 6 to 10 and more. On average, there were 3 children in care (SD = 2.17).

Other than Dary and Pashtu-speaking respondents, there were a negligible number of respondents from "other" language communities. The Dary-speaking group comprised $90 \%$ of the sample. The two main groups did not differ significantly on their average age and number of children in the household.

Males comprised over $70 \%$ of the sample. Note that this number reflects the usual respondent to the survey, rather than the gender representation in the households of the sample. There were no data on shared households. This higher number of male respondents should be kept in mind when interpreting the overall slightly higher educational level of males in the sample (See Table 1). Male and female respondents did not differ on average age or average number of children in the household they were representing.

Practically, $100 \%$ of the respondents indicated it is important for them to understand their children better. Ninety-nine percent agreed it is important to know more about child rearing, and 96\% agreed to participate in the M-learning trial.

Patterns of parenting behaviors for gender group (male, coded as 1 ; female, coded as 2) and education level 
Table 1. Percentage male, female and total respondents at different education levels.

\begin{tabular}{cccc}
\hline & Male N $=156$ & Female N $=58$ & Total N $=214$ \\
Graduate degree & 4 & & 3 \\
University degree & 28 & 16 & 24 \\
Grade 12 & 31 & 33 & 32 \\
Some education & 4 & & 3 \\
No education but literate & 24 & 28 & 25 \\
No education and not literate & 9 & 24 & 13 \\
\hline
\end{tabular}

(highest education-level was coded as 1) were explored by correlating each variable with the frequency indicated by respondents for each behavioural occurrence (never, when I can, sometimes, most of the time, always). Results from these exploratory analyses are displayed in Table 2.

Results of our interviews demonstrated that in Afghanistan the males in the family (father, elder brother, others) have more to say and do with respect to the upbringing of their children than the women in the family.

\section{Discussion}

In the past, childrearing in early ages was mostly confined to nutrition, health and hygiene, until recent years when Piaget, Erikson and others cultivated modern theories of developmental psychology (UNESCO, 2007). Today, scientific research has confirmed that the ages from birth to 7 are the most important years in the formation of human personality and behaviour (Brierley, 2004). Therefore, it is of the utmost importance that parents have a clear understanding of domains other than nutrition, health and hygiene in the upbringing of their children. These domains include physical, emotional, social, cognitive and language development. Brain research has demonstrated that the first five years of life have a crucial impact on children and their later development (PCD, 2011-2012). The understanding and implementation of these modern theories on specific domains of development are simpler in developed countries, due to the high numbers of educated parents, powerful media and social groups/networks. In developing countries however, the need for implementation and dissemination of knowledge, with respect to child development, particularly when it pertains to modern theories of child development, is crucial (Cheung et al., 2007).

We believe Afghanistan is no different than other developing countries with respect to the need for understanding and implementation of developmental theories of childrearing. Afghanistan may in fact be more in need of this knowledge and dissemination of learning, since four generations of Afghan parents have been deprived of education and literacy.

Afghan citizens were not only deprived of education during these four decades, for also many of their traditional values were lost to extreme ideologies. As a result, the children of these families have been most affected and we believe it is of the utmost importance for all parents in developing countries to have access to knowledge and understanding of modern theories of child development. Evidence suggests that the world would be a better place if we could pay more attention to the development of children from birth to age 7 (Aber et al., 2013). This is why one of the specific aims of this study was to determine the parenting practices of Afghan parents relative to contemporary developmental theories and whether Afghan families would be open to receiving modern theories through technological advances.

It is of common understanding that mothers are the center of the family and have a controlling role in the development and upbringing of their children. Results of our study demonstrated that in Afghanistan, the males in the family (father, elder brother, others) have more to say and do with respect to the upbringing of their children than the women in the family. Women's responsibilities are limited to loving and caring, preparing food, washing clothes and giving affection; however, when it comes to the major decision making process in other developmental domains, responsibility goes to the man. This is probably why our results showed that males are more aware of and have more knowledge about the development of children than females in the family.

The correlational analyses in this study aimed to clarify the relations of parenting behaviours from frequency of occurrence to gender and education level (Table 2). Amongst 15 behavioural patterns evaluated, four show 
Table 2. Relations of parenting behaviors frequency of occurrence to gender and education level.

\begin{tabular}{|c|c|c|}
\hline \multirow{2}{*}{ Items } & \multicolumn{2}{|c|}{ Correlations with: } \\
\hline & Gender & Education \\
\hline \multicolumn{3}{|l|}{ Nurture } \\
\hline I clearly communicate my needs to my child & -0.06 & -0.05 \\
\hline I tune into my child's emotional needs. & -0.03 & -0.12 \\
\hline I give my child the physical affection he/she needs. & -0.11 & -0.12 \\
\hline I control my temper when angry with my child. & -0.12 & -0.05 \\
\hline I actively build my child's self-image and confidence level. & $-0.14^{*}$ & $-0.26^{* *}$ \\
\hline I take responsibility for my own mistakes and apologize. & $-0.16^{*}$ & -0.12 \\
\hline I teach my child to respond out of love, not out of fear. & -0.10 & $-0.14^{* *}$ \\
\hline I support my child through difficult social situations. & -0.11 & -0.12 \\
\hline I tell my child "I love you" each and every day. & -0.09 & -0.11 \\
\hline \multicolumn{3}{|l|}{ Structure } \\
\hline I work with my child to solve difficult issues at home. & 0.01 & $-0.14^{*}$ \\
\hline I am consistent in limit setting and discipline. & -0.02 & $-0.21^{* *}$ \\
\hline I follow through with my child & 0.09 & -0.02 \\
\hline I respond in a productive manner to sibling rivalry. & -0.04 & -0.13 \\
\hline I avoid giving my child silent “don't” messages & -0.13 & -0.08 \\
\hline I take responsibility to reduce the stress level in my home & -0.11 & -0.02 \\
\hline
\end{tabular}

strong significance $(p<0.05$ and $p<0.01)$, and five borderline correlations in favour of educated participants. This means that educated parents are more inclined to follow modern parenthood practices than less literate participants. This relationship between behavioural patterns and gender was significant $(p<0.05)$ only in two occasions, and marginally significant in two occasions, in favour of male participants. This means that male participants followed the modern parenthood practice more than females. Furthermore, the results of individual interviews indicated that $100 \%$ of the population in this study regard with less importance the level of education and gender, and would like to learn more about modern theories and practices of childrearing.

The first direction coming out of this study is to provide education with respect to childrearing to the female members of the family. Analyzing the data, we believe it is of the utmost importance to educate mothers in modern developmental theories. This will have two substantial benefits. Firstly, it will strengthen the role of the mother in the family dynamic and make her an integral part of the decision making body in the upbringing of her children. Secondly, it will also support the male member of the family, who is the only person working outside of the home, the only bread maker of the family. Leaving the domestic responsibilities of the children to a knowledgeable wife/female member of the family would give more opportunities to the male in the family to manage the important and difficult problems outside the house. Having said that, our analysis also showed that it would be counterproductive to design these programs ONLY for female members of the family. We believe it is very important that males take the same courses and obtain the same knowledge as the female members of the family for two important reasons. One, as we discovered in this study, males are the decision makers in the family and have greater knowledge. Since we don't want to leave them behind, we need to make them an integral part of the new development. On the other hand, we would like males and females to be on the same page. Only in this kind of family dynamics, where both parents are involved and the mother can take the leading role on childrearing, can we improve future generations and support society as a whole. 
The second recommendation for future direction coming out of this study is to put extra effort towards teaching the illiterate and uneducated parents modern theories of childrearing. So far the attention of the world has been cast toward the education of educated populations, due to the assumption that it would be too difficult, even impossible, to teach modern theories of development to those who have absolutely no educational background or are illiterate. With this assumption, the core of the population, those most in need of education on childrearing, were ignored entirely (Millennium Development Goals, 2012). In this study, results demonstrated that all of less educated and illiterate participants would like to learn more on modern theories of childrearing and would be happy to use the new and innovative technologies to learn how to better raise their children. This indicates that with innovative technology such as M-Learning (learning through mobile phones) we can deliver complex theoretical and educational curriculum in subjects such as developmental theories to illiterate and uneducated populations who are in desperate need of such knowledge. Empowering Afghan mothers, particularly those who are illiterate, will change future generations of Afghanistan for years to come.

\section{Summary and Conclusions}

In conclusion, the results of our study indicate that child rearing rates are very high in the value system of Afghans. It also demonstrated that the parenting practices of higher educated participants were more in line with modern child rearing practices, and that female populations (mothers) and less educated participants are in great need of this type of educational intervention. In addition our study has shown not only the need for this type of education but also the keen willingness to learn, regardless of their level of education, gender or language. Afghan parents are open to dissemination and implementation of this type of knowledge, through modern technologies where literacy is not a stumbling block for receiving and understanding this type of information.

\section{References}

Aber, J. L., Campion, K., Klaus, S., \& Lombardi, J. (2013). A New Global Development Goal for the World's Youngest Children. Washington DC: Institute of Medicine and National Academy of Sciences.

Brierley, J. K. (2004). Give Me a Child Until He Is Seven: Brain Studies and Early Childhood Education (2nd ed.). Reprinted by Routledge Falmer Milton Park, Abingdon, Oxon.

Cheung, Y. B., Cueto, S., Glewwe, P., Grantham-McGregor, S., Richter, L., Strupp, B., \& the International Child Development Steering Group (2007). Child Development in Developing Countries 1: Developmental Potential in First 5 Years for Children in Developing Countries. Lancet, 369, 60-70.

Cree, A., Kay, A., \& Steward, J. (2012). The Economic \& Social Cost of Illiteracy: A Snapshot of Illiteracy in a Global Context (Final Report from the World Literacy Foundation).

Jacobson, G. C. (2011). ISAF Spokesman Discusses Progress in Afghanistan. International Security, Assistance Force/NATO. 25 July 2011.

Ki-Moon, B. (2007). Children and the Millennium Development Goals: Progress toward A World Fit for Children. Secretary-General of United Nations, United Nations.

Millennium Development Goals Report 2012 (Afghanistan). Directorate of Policy and Evaluation in General Directorate of Policy, Monitoring and Evaluation of Afghanistan National Development Strategy Islamic Republic of Afghanistan Ministry of Economy Kabul Afghanistan, 2012. “Millennium Development Goals”. StudyMode.com. 03, 2012. http://www.studymode.com/essays/Millenium-Development-Goals-934889.html

Palau, G. R. (2013). Afghanistan Team Leader \& Social and Strategic Infrastructure Desk Officer: Displacement in Afghanistan: Post-2014 Origins, Current Situation and Potential Flows.

The Partnership for Child Development (PCD) (2011-2012). Sharing Ideas Guiding Change, School of Public Health, Imperial College London, Faculty of Medicine, Norfolk Place. Annual Report 2011-2012, London.

Smith, S. C., \& Todaro, M. P. (2009). Economic Development. Pearson (10th ed).

UNESCO (2007). Strong Foundation: Early Childhood Care and Education; Education for All Global Monitoring Report 2007.

UNICEF Report on Education in Afghanistan (2007). Accessed via United Nations Children's Fund (UNICEF). http://www.unicef.org/infobycountry/files/Updated_2007_QandA_Afghanistan.pdf 